\title{
Spectrum of vulvar lesions: a clinicopathologic study of 170 cases
}

\author{
Harsh Mohan ${ }^{1}$, Reetu Kundu ${ }^{1}$, Komal Arora ${ }^{1}$, Rajpal Singh Punia ${ }^{1}$, Anju Huria ${ }^{2}$
}

${ }^{1}$ Department of Pathology, ${ }^{2}$ Department of Obstetrics \& Gynecology, Government Medical College and Hospital, Sector 32-A, Chandigarh-160030, India

Received: 25 January 2014

Accepted: 2 February 2014

*Correspondence:

Dr. Reetu Kundu,

E-mail: reetukundu@gmail.com

(C) 2014 Mohan $\mathrm{H}$ et al. This is an open-access article distributed under the terms of the Creative Commons Attribution Non-Commercial License, which permits unrestricted non-commercial use, distribution, and reproduction in any medium, provided the original work is properly cited.

\begin{abstract}
Background: A wide range lesions may occur in the vulvar region. The clinician is often confronted with the challenge to draw a distinction between normal variants, benign entities and a potentially serious pathology. The aim of the present study is to have an insight into the diverse morphologic spectrum of vulvar lesions.

Methods: The present retrospective study was carried out by compiling the data from archival records over a period of eight years from January 2005 to December 2012. The vulvar biopsies/vulvectomy specimens were studied for histomorphological features. The lesions were categorized as non neoplastic, neoplastic and inconclusive; neoplastic ones were further divided into benign, malignant and premalignant.

Results: The age of the women ranged from 6 to 80 years (mean 38.2 \pm 6.4 ) with the maximum number of patients between 31 to 40 years of age. Most common clinical presentation was itching and white plaque on the vulva (85 cases; $50 \%$ ). The commonest site of vulval lesions was labia majora (87 cases, $51.18 \%)$. Non neoplastic lesions were more common $(n=94 ; 55.29 \%)$ than the neoplastic lesions $(n=50 ; 29.41 \%)$. There were $23(46 \%)$ benign lesions while 27 cases $(54 \%)$ were malignant or premalignant ones. In 26 cases, no definitive histologic diagnosis could be rendered.

Conclusion: Early recognition of vulvar lesions and a prompt biopsy diagnosis for all lesions with suspicious changes is of great significance. The term leukoplakia is imprecise and should be replaced by a precise histological description.
\end{abstract}

Keywords: Vulvar, Biopsy, Neoplastic, Non neoplastic, Histomorphology

\section{INTRODUCTION}

A wide range of benign, premalignant and malignant lesions may occur in the vulvar region. The most common symptom of both benign and malignant vulvar lesions is vulval itching. ${ }^{1}$ The spectrum of vulvar lesions is large, ranging from dystrophy to a frank carcinoma. Vulvar dystrophy refers to a clinically related group of disorders of epithelial growth that usually present as white lesions and hence the older terminology of leukoplakia. Vulvar carcinoma is encountered most frequently in postmenopausal women. ${ }^{2}$
The clinician is often faced with the challenge to make a distinction between normal variants, benign entities and a potentially serious pathology. The general approach for evaluation of vulval lesions includes a pertinent clinical history, physical examination and diagnostic studies. ${ }^{3}$ In lesions clinically suspicious for malignancy (asymmetry, border irregularity, color variation, rapid change, bleeding, non-healing) one or more vulvar biopsies are recommended. The biopsy should be strongly considered in cases where a diagnosis cannot be made confidently on visual inspection and by non invasive methods or if the lesion does not resolve after standard therapy. It is 
extremely beneficial to establish the diagnosis by biopsy early, as the clinical features may change over time. The present study is undertaken to describe the histopathological findings in vulvar biopsies and further categorize the spectrum of vulvar lesions.

\section{METHODS}

The present retrospective study compiles the data from archival records over a period of eight years from January 2005 to December 2012. The clinical data including the age, patients' complaints, findings on general physical examination and local examination along with the clinical possibilities were noted from the file records.

A total of 171 biopsies and 2 vulvectomy specimens received from 170 patients were reviewed. In one patient a repeat biopsy was received. In 2 cases, biopsy diagnosis was followed by vulvectomy. Routine hematoxylin and eosin staining was done on sections from paraffin embedded and formalin fixed tissues. Serial sections and special stains were done wherever required.

\section{RESULTS \\ Clinical features}

The age of the women ranged from 6 to 80 years (mean 38.2 , $95 \%$ confidence interval for mean, 31.8 to 44.6 ) with the maximum number of patients between 31 to 40 years of age. Most common clinical presentation was itching and white plaque on the vulva (85 cases; $50 \%$ ); other presentations being swelling, nodularity, ulcer and discharge. The commonest site of vulval lesions was labia majora (87 cases, $51.18 \%$ ) followed by labia minora (73 cases, $42.94 \%$ ). In 6 cases the biopsies were taken from multiple sites including clitoris, fourchette, labia majora and labia minora. Two biopsies were from perineal area and one from mons pubis. In one case the site of biopsy was episiotomy scar.

\section{Pathological findings}

In 170 women who underwent vulvar biopsy, a spectrum of lesions (benign and malignant, neoplastic and nonneoplastic) was noted as shown in Table 1.

Table 1: Histopathological diagnosis in vulvar lesions $(\mathbf{n = 1 7 0})$.

\begin{tabular}{|c|c|c|}
\hline Non Neoplastic ( $\mathrm{n}=\mathbf{9 4} ; \mathbf{5 5 . 2 9 \%}$ ) & \multicolumn{2}{|l|}{ Neoplastic ( $\mathrm{n}=50 ; 29.41 \%)$} \\
\hline Diagnosis, Number of cases $(\%)$ & Benign $(n=23 ; 46 \%)$ & $\begin{array}{l}\text { Malignant \& Pre } \\
\text { malignant } \\
(n=27 ; 54 \%)\end{array}$ \\
\hline \multirow{9}{*}{$\begin{array}{l}\text { LSA, } 36(38.30 \%) \\
\text { Squamous Hyperplasia, } 17(18.09 \%) \\
\text { Mixed dystrophy, } 1(1.06 \%) \\
\text { Lichen Planus, } 3(3.19 \%) \\
\text { Bartholin's Cyst, } 14(14.89 \%) \\
\text { Gartner cyst, } 1(1.06 \%) \\
\text { Mullerian cyst, } 1(1.06 \%) \\
\text { Nabothian cyst, } 1(1.06 \%) \\
\text { Mucous cyst, } 4(4.26 \%) \\
\text { Mesonephric duct cyst, } 1(1.06 \%) \\
\text { Vasculitis (Behcet's disease), } 2(2.13 \%) \\
\text { Epidermal inclusion cyst, } 2(2.13 \%) \\
\text { Hidradenitis suppurativa, } 1(1.06 \%) \\
\text { Cysticercosis, } 1(1.06 \%) \\
\text { Vulval elephantiasis, } 1(1.06 \%) \\
\text { Scar tissue, } 1 \text { (1.06\%) } \\
\text { Non-specific Vulvitis, } 7(7.45 \%)\end{array}$} & Fibroepithelial Polyp, 12 (52.17\%) & $\begin{array}{l}\text { Vulvar Intraepithelial } \\
\text { Neoplasia } 6(22.22 \%)\end{array}$ \\
\hline & Apocrine hidrocystoma, 1 (4.35\%) & $\begin{array}{l}\text { Squamous cell } \\
\text { carcinoma } 17(62.96 \%)\end{array}$ \\
\hline & Angiokeratoma, $1(4.35 \%)$ & $\begin{array}{l}\text { Microinvasive SCC } \\
1(3.70 \%)\end{array}$ \\
\hline & Hidradenoma Papilliferum, 3 (13.04\%) & $\begin{array}{l}\text { Verrucous carcinoma } \\
1(3.70 \%)\end{array}$ \\
\hline & Aggressive angiomyxoma, 3 (13.04\%) & \multirow{4}{*}{$\begin{array}{l}\text { Condyloma acuminatum } \\
2(7.41 \%)\end{array}$} \\
\hline & Neurofibroma, $1(4.35 \%)$ & \\
\hline & Cavernous hemangioma, $1(4.35 \%)$ & \\
\hline & Leiomyoma, $1(4.35 \%)$ & \\
\hline & Descriptive $(n=26 ; 15.30 \%)$ & \\
\hline
\end{tabular}

Amongst the non-neoplastic lesions, the most common histopathologic diagnosis was of lichen sclerosus et atrophicus (LSA) (36 cases; 38.30\%). Microscopic examination in these cases revealed atrophic epithelium with flattening of rete ridges, varying degrees of surface keratinization and subepithelial edema. The next in frequency was squamous hyperplasia (17 cases; $18.09 \%$ ). In one case where multiple biopsies were undertaken, a diagnosis of LSA was made on left sided biopsy and squamous hyperplasia on right sided biopsy. In another case, a diagnosis of mixed dystrophy on single biopsy was rendered. In this case, the biopsy showed hypertrophic changes in some areas with lichen sclerosis in other areas. Three cases were diagnosed as lichen planus where the biopsy revealed a band-like inflammatory infiltrate at the dermo-epidermal junction. Among the cystic lesions, a diagnosis of Bartholin cyst was rendered in 14 cases $(14.89 \%)$ where the biopsy showed cyst lined by transitional to low cuboidal epithelium. Other cases with cysts included four cases of 
mucous cyst with endocervical type columnar epithelial lining and cytoplasmic mucin, two cases of epidermal inclusion cyst and one case each of mesonephric duct cyst, mullerian cyst, nabothian cyst and Gartner cyst. One case was suggestive of a parasitic cyst on histopathology which showed palisading histiocytes without any parasite parts. This case was of a 6 yrs old girl, previously diagnosed on aspiration cytology as cysticercosis of mons pubis based on the fragments of cysticercus in the aspirate. One case suggestive of vulval elephantiasis showed dense collagenization of dermis and subcutis with numerous dilated lymphatics and patchy mixed inflammation; other findings were presence of a few non caseating granulomas with foreign body giant cells (Figure 1). The filarial antigen serology was subsequently found to be positive in this case. One case diagnosed as hidradenitis suppurativa revealed hyperplastic squamous epithelium, follicular keratosis, follicular plugging and dilatation along with dense perifollicular inflammatory infiltrate and focal abscesses. Two biopsies had the clinical suspicion of Behcet's disease. Microscopically both these biopsies showed neutrophilic invasion of blood vessel walls, presence of disrupted neutrophils (leukocytoclasia), extravasation of red blood cells and fibrinoid necrosis of the blood vessel wall. Seven cases revealed nonspecific inflammation and were diagnosed as non-specific vulvitis.

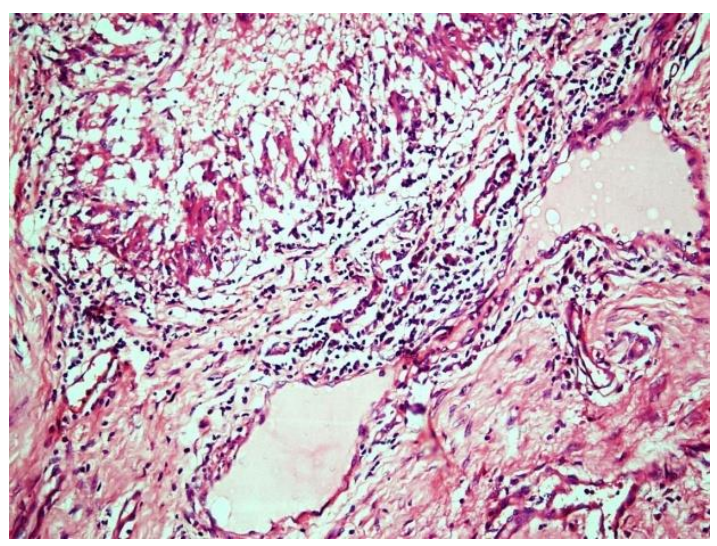

Figure 1: Vulval elephantiasis: Photomicrograph showing dilated lymphatic channels, histiocytic granuloma formation and mixed inflammatory cell infiltrate in the dermis $(\mathrm{H} \& \mathrm{E}, \mathrm{x200})$.

Among the neoplastic benign lesions, the most common tumor was fibroepithelial polyp in 12 cases $(52.17 \%)$ followed by three cases $(13.04 \%)$ each of hidradenoma papilliferum and aggressive angiomyxoma. One case each of apocrine hidrocystoma, angiokeratoma (Figure 2), cavernous hemangioma, leiomyoma and neurofibroma (Figure 3) was reported. Microscopically, fibroepithelial polyps showed lesion with connective tissue stalk containing blood vessels and loose collagen covered by keratinized stratified squamous epithelium. Microscopically, hidradenoma papilliferum showed a well circumscribed lesion composed of a cystic space containing papillary structures having delicate fibrovascular branching stalks. There were numerous tubules and acini lined by inner columnar epithelium with an outer compressed layer of myoepithelial cells. The biopsies in three cases of aggressive angiomyxoma revealed an infiltrative, poorly circumscribed tumor composed of bland spindle to stellate cells along with blood vessels of varying caliber, embedded in a hypocellular myxoid stroma. There was no evidence of atypia or significant mitoses in these cases. The background stroma stained positively with alcian blue.

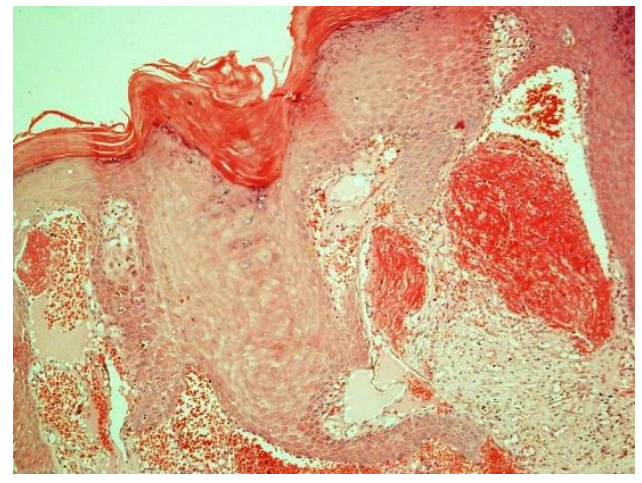

Figure 2: Angiokeratoma: Photomicrograph showing ectatic blood vessels in papillary dermis with hyperplastic overlying epidermis (H\&E, x100).

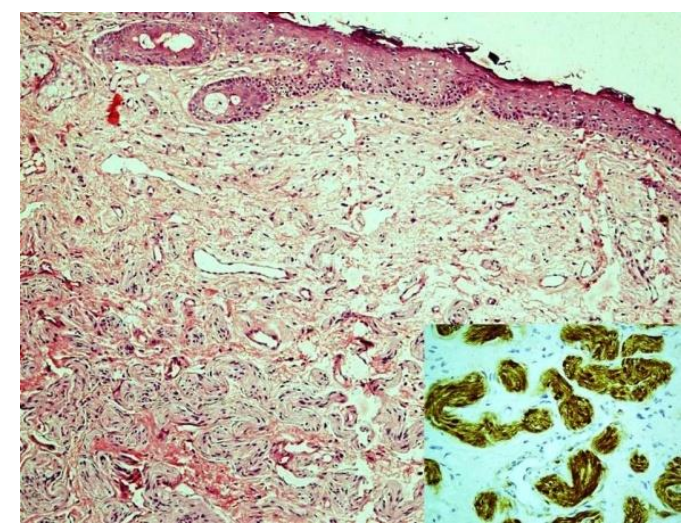

Figure 3: Neurofibroma: Photomicrograph showing non encapsulated tumor in the dermis composed of loosely arranged spindle cells with twisted nuclei and wavy collagenous strands $(H \& E, x 100)$. Strong nuclear and cytoplasmic positivity on $\mathrm{S}-100$ immunostain in the inset (IHC, x400).

Two cases of condyloma acuminatum were diagnosed. The biopsy revealed hyperkeratosis, acanthosis and papillomatosis of the stratified squamous epithelium with keratinocytes having a distinct vacuolated cytoplasm containing a pyknotic nucleus surrounded by a halo (koilocyte). Six cases $(22.22 \%)$ were diagnosed as vulvar intraepithelial neoplasm (VIN) where the biopsies revealed a full thickness squamous dysplasia with no invasion of the underlying basement membrane (Figure $4 \& 5$ ). Squamous cell carcinoma was seen in 17 (62.96\%) cases and one case each of microinvasive squamous cell carcinoma and verrucous carcinoma (Figure 6) was diagnosed. 


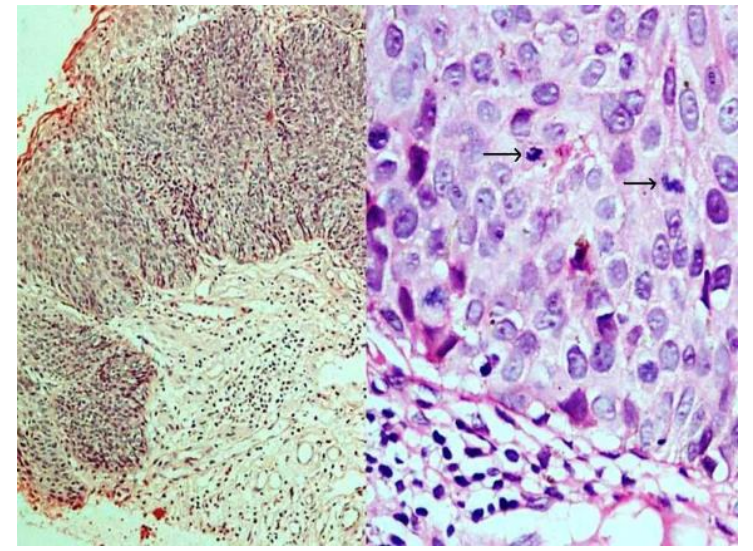

Figure 4: VIN 2: Photomicrograph showing thickened epithelium with disarray of keratinocytes and an intact

basement membrane on the left $(H \& E$, x100) and

higher magnification showing large atypical

keratinocytes with vesicular nuclei having conspicuous nucleoli and mitoses (arrow) on the right (H\&E, x400).

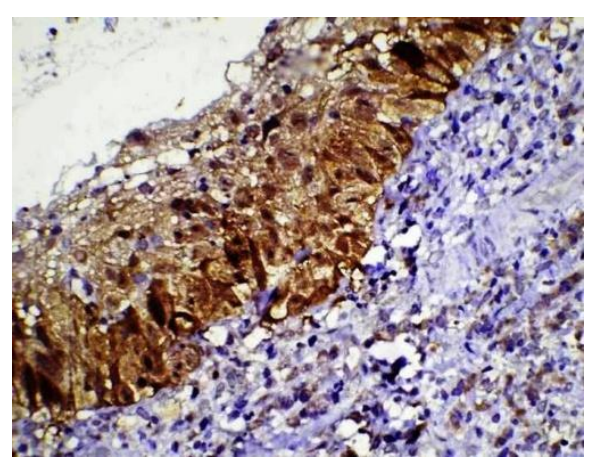

Figure 5: VIN 3: Intense granular nuclear and cytoplasmic positivity on p16 immunostaining in HPV associated VIN (IHC, x200).

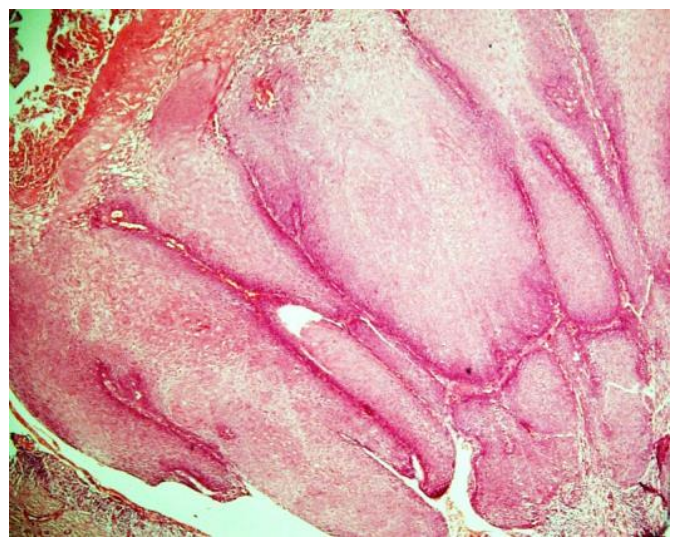

Figure 6: Verrucous carcinoma: Photomicrograph showing large bulbous downward proliferations into the underlying dermis, well delineated from the surrounding stroma $(\mathrm{H \& E}, \mathrm{x40})$.

Twenty six cases $(15.30 \%)$ in which a definitive histologic diagnosis could not be reached were rendered as inconclusive on histopathologic biopsy for various reasons such as non-representative or inadequate biopsy. One such descriptive biopsy was followed by a repeat biopsy based on high clinical suspicion of carcinoma. The repeat biopsy revealed squamous cell carcinoma (SCC). Two biopsies where diagnosis of SCC was given were followed by vulvectomy specimens.

\section{DISCUSSION}

Patients with vulval disorders are well managed by a multidisciplinary approach with the expertise of both gynecologist and dermatologist. ${ }^{4}$ Dermatitis affecting vulva may occur at any age and is not uncommon. The development of cancer subsequent to clinical presentation of dermatosis is a well known phenomenon. The opinion of a histopathologist with a keen interest in this arena is of paramount importance..$^{5}$ Most of the authors have emphasized the role of vulvar skin biopsy with subsequent histologic analysis by a dermatopathologist in diagnosing vulvar diseases. ${ }^{6,7}$

A biopsy is mandatory for assessment of invasion in neoplastic vulvar epithelial lesions. For an accurate diagnosis, judicious selection of biopsy sample locations is important. ${ }^{8}$ For palpable tumors, biopsy should contain the tumor mass with surrounding normal skin to comment on the extent of invasion. In patients with indistinct tumor boundaries, topical agents like diluted acetic acid may be used for identification of acetowhite/suspicious areas. Toluidine blue may be used for identifying dysplastic tissue which can be biopsied. ${ }^{8,9}$

There was a wide age range of 6 to 80 years (mean $38.2 \pm 6.4)$ in the present study. A significant number of women were post menopausal $(38 \%)$ which is usually the case. ${ }^{9}$ One hundred forty four $(84.70 \%)$ women had disease of the skin or vulvar mucosa identified on histopathology and $26(15.30 \%)$ of women had non-specific findings. This is low but it can be as high as $39 \%$. $^{6}$ The most common dermatologic conditions encountered in our study were lichen sclerosus, spongiotic dermatitides, atopic dermatitis and lichen planus as reported in other studies. ${ }^{5,6,10}$ Lichen sclerosus was seen in $32 \%$ patients, which is higher than observed in some studies because women in our country do not admit to symptomatology in early stage. ${ }^{10}$ Biopsies in cases of lichen sclerosus are useful for confirmation of clinical diagnosis and to exclude early invasive malignancy.

Primary lesions are diagnosed on histolopathology using nomenclature given by The International Society for the Study of Vulvar Diseases which has emphasized that there is no evidence that the VIN 1-3 morphologic spectrum reflects a biologic continuum. ${ }^{11,12}$ The Vulvar Intraepithelial Neoplasia (VIN) is divided into 3 grades depending on the extent of thickness of epithelium involved in neoplastic process. Extension of the neoplastic cells into the stroma is invasive vulvar cancer. VIN 3 or full thickness dysplasia may be warty, basaloid and differentiated. The distinction between VIN lesions and early invasive SCC can only be done on histopathologic examination, hence necessitating a 
biopsy of all suspicious vulvar lesions. Furthermore, the erosive forms of VIN might indicate start of tumor invasion and hence a mandatory biopsy. ${ }^{13}$ In our study VIN was seen in six cases while early invasive SCC was reported in a single case.

For appropriate intervention and effective management with decreased morbidity and mortality, an early definitive diagnosis of vulvar cancer is necessary. Lichen sclerosus is commonly seen associated with differentiated-type VIN, which may be misdiagnosed as lichen sclerosus or other benign dermatosis. The number of carcinoma cases associated with differentiated-type VIN outnumbers those with lichen sclerosus. ${ }^{14}$ Lichen sclerosus with dyskeratosis and/or parakeratosis, hyperplasia and basal cellular atypia on histopathologic examination warrants a close follow-up due to increased risk for malignant progression. The estimated risk is around 5\%. ${ }^{15}$ Follow-up does not prevent neoplastic change in women with lichen sclerosus but helps in early detection of any malignant transformation. ${ }^{16}$

Squamous cell carcinoma comprises about $90 \%$ of all vulval cancers, the others being melanoma, Paget's disease, Bartholin's gland tumour, adenocarcinoma and basal cell carcinoma. ${ }^{15,17}$ The most common type of vulvar squamous carcinoma is keratinizing type associated with differentiated VIN or a vulvar dystrophy. ${ }^{18-20}$ Verrucous carcinoma is seen in $<1 \%$ cases. ${ }^{15}$ In our study vulvar squamous cell carcinoma was seen in 17 cases while verrucous carcinoma was reported in a single case. In one study out of 55 vulvar biopsies SCC was seen in six of the cases. ${ }^{2}$

Two pathways seem to play a role in development of vulvar cancer. The first one leads mainly to nonkeratinizing, basaloid and/or warty carcinomas usually affecting young females. Infection with high-risk human papilloma viruses like HPV 16 and 18 is involved. These cancers are associated with warty and/or basaloid VIN, also known as classic/bowenoid VIN. As per the latest terminology, HPV-positive VIN lesions are called VIN, usual type. The prognosis is better in vulvar squamous cell carcinomas which are HPV-positive. The other pathway leads to mostly differentiated keratinizing squamous cell carcinoma developing in a background of nonneoplastic epithelial disorders like lichen sclerosus. These tumors are rarely associated with high-risk HPV and affect older females. The precursor form is called simplex/well differentiated VIN often difficult to distinguish from benign vulvar lesions like lichen sclerosus. ${ }^{11,21}$

The task of making a distinction between normal variants, benign entities and potentially serious vulvar pathology is challenging. Early recognition of vulvar lesions and a prompt biopsy diagnosis with subsequent histologic analysis by a dermatopathologist is advocated. The term leukoplakia is imprecise and confusing and should be replaced by precise histological description. Considering the psychosexual impact of vulvar neoplasia and given the association of dermatosis and vulvar squamous cell carcinoma, lesions with suspicious changes warrant a biopsy diagnosis.

Funding: None

Conflict of interest: None declared

Ethical approval: Not required

\section{REFERENCES}

1. Hanprasertpong J, Chichareon S, Wootipoom V, Buhachat R, Tocharoenvanich S, Geater A. Clinicopathological profile of vulva cancer in southern Thailand: analysis of 66 cases. J Med Asso Thai 2005;88(5):575-81.

2. Mohan RB, Amitava M, Kumar SB. Clinicopathological analysis of vulval lesions - A 5 year analysis in a tertiary teaching hospital. J Obstet Gynecol India 2006;56(5):440-42.

3. Leighton PC, Langley FA. A clinico-pathological study of vulval dermatoses. J Clin Path 1975;28:394-402.

4. Iyengar S, Acheson N. Premalignant vulval conditions. Obstet Gynaecol Reprod Med 2008;18(3):60-3.

5. Olsson A, Selva-Nayagam P, Oehler MK. Postmenopausal vulval disease. Menopause International 2008;14(4):169-72.

6. Bowen AR, Vester A, Marsden L, Florell SR, Sharp $\mathrm{H}$, Summers $\mathrm{P}$. The role of vulvar skin biopsy in the evaluation of chronic vulvar pain. Am J Obstet Gynecol 2008;199:467.

7. Kelekci KH, Adamhasan F, Gencdal S, Sayar H, Kelekci S. The impact of the late classification system of benign vulvar diseases on the management of women with chronic vulvar pruritus. Indian $\mathbf{J}$ Dermatol Venereol Leprol 2011;77:294-9.

8. Tyring SK. Vulvar squamous cell carcinoma: Guidelines for early diagnosis and treatment. Am J Obstet Gynecol 2003;189:S17-S23.

9. Acheson N, Ganesan R, Chan KK. Premalignant vulvar disorders. Curr Obstet Gynaecol 2000;10(1):12-7.

10. O'Keefe RJ, Scurry JP, Dennerstein G, Sfameni S, Brenan J. Audit of 114 non-neoplastic vulvar biopsies. Br J Obstet Gynecol 1995;102(10):780-6.

11. Del Pino M, Rodriguez-Carunchio L, Ordi J. Pathways of vulvar intraepithelial neoplasia and squamous cell carcinoma. Histopathology 2013;62(1):161-75.

12. Westermann C, Fischer A, Clad A. Treatment of vulvar intraepithelial neoplasia with topical 5\% imiquimod cream. Int $\mathbf{J}$ Gynaecol Obstet 2013;120(3):266-70.

13. Spencer RJ, Young RH, Goodman A. The risk of squamous cell carcinoma in persistent vulvar ulcers. Menopause 2011;18(10):1067-71.

14. Kokka F, Singh N, Faruqi A, Gibbon K, Rosenthal AN. Is differentiated vulval intraepithelial neoplasia the precursor lesion of human papillomavirus- 
negative vulval squamous cell carcinoma? Int $\mathrm{J}$ Gynecol Cancer 2011;21:1297-305.

15. Robinson Z, Edey K, Murdoch J. Invasive vulval cancer. Obstet Gynaecol Reprod Med 2011;21(5):129-36.

16. Jones RW, Scurry J, Neill S, MacLean AB. Guidelines for the follow-up of women with vulvar lichen sclerosus in specialist clinics. Am J Obstet Gynecol 2008;198:496.e1-496.e3.

17. Judson PL, Habermann EB, Baxter NN, Durham $\mathrm{SB}$, Virnig BA. Trends in the incidence of invasive and in situ vulvar carcinoma. Obstet Gynecol 2006; 107:1018-22.

18. Baldwin P, Latimer J. Vulval cancer. Current Obstetrics \& Gynaecology 2005;15:113-22.
19. Simcock B. Invasive vulval cancer. Obstet Gynaecol Reprod Med 2008;18(3):64-8.

20. Chiesa-Vottero A, Dvoretsky PM, Hart WR. Histopathologic study of thin vulvar squamous cell carcinomas and associated cutaneous lesions: a correlative study of 48 tumors in 44 patients with analysis of adjacent vulvar intraepithelial neoplasia types and lichen sclerosus. Am J Surg Pathol 2006;30(3):310-8.

21. van der Avoort IAM, Shirango H, Hoevenaars BM, Grefte JM, de Hullu JA, de Wilde PC, et al. Vulvar squamous cell carcinoma is a multifactorial disease following two separate and independent pathways. Int J Gynecol Pathol 2006;25(1):22-9.

DOI: $10.5455 / 2320-1770$. ijrcog20140335

Cite this article as: Mohan H, Kundu R, Arora K, Punia RS, Huria A. Spectrum of vulvar lesions: a clinicopathologic study of 170 cases. Int J Reprod Contracept Obstet Gynecol 2014;3:175-80. 